Research Article

\title{
Drought Early Warning and the Timing of Range Managers' Drought Response
}

\author{
Tonya R. Haigh (D), ${ }^{1}$ Jason A. Otkin $(D),{ }^{2}$ Anthony Mucia $\left(\mathbb{D},{ }^{3}\right.$ Michael Hayes, ${ }^{4}$ \\ and Mark E. Burbach ${ }^{5}$ \\ ${ }^{1}$ National Drought Mitigation Center, University of Nebraska-Lincoln, Lincoln 68583, USA \\ ${ }^{2}$ Cooperative Institute for Meteorological Satellite Studies, Space Science and Engineering Center, \\ University of Wisconsin-Madison, Madison 53706, USA \\ ${ }^{3}$ CNRM UMR 3589, Météo-France/CNRS, Toulouse 31057, France \\ ${ }^{4}$ School of Natural Resources, University of Nebraska-Lincoln, Lincoln 68583, USA \\ ${ }^{5}$ Conservation and Survey Division, School of Natural Resources, University of Nebraska-Lincoln, Lincoln 68583, USA
}

Correspondence should be addressed to Tonya R. Haigh; thaigh2@unl.edu

Received 1 March 2019; Revised 15 July 2019; Accepted 25 July 2019; Published 9 October 2019

Guest Editor: Jayant K. Routray

Copyright $\odot 2019$ Tonya R. Haigh et al. This is an open access article distributed under the Creative Commons Attribution License, which permits unrestricted use, distribution, and reproduction in any medium, provided the original work is properly cited.

The connection between drought early warning information and the timing of rangeland managers' response actions is not well understood. This study investigates U.S. Northern Plains range and livestock managers' decision-making in response to the 2016 flash drought, by means of a postdrought survey of agricultural landowners and using the Protective Action Decision Model theoretical framework. The study found that managers acted in response to environmental cues, but that their responses were significantly delayed compared to when drought conditions emerged. External warnings did not influence the timing of their decisions, though on-farm monitoring and assessment of conditions did. Though this case focused only on a one-year flash drought characterized by rapid drought intensification, waiting to destock pastures was associated with greater losses to range productivity and health and diversity. This study finds evidence of unrealized potential for drought early warning information to support proactive response and improved outcomes for rangeland management.

\section{Introduction}

The goal of monitoring and early warning of natural hazards is the provision of reliable and timely information to inform decision-making in ways that reduce harm of loss [1]. Scientists recommend that agricultural producers, like other resource managers, use climate data as well as on-site observations to monitor and predict drought in order to manage it effectively and minimize damages $[2,3]$. In the U.S., for example, monitoring tools such as the U.S. Drought Monitor [4] and NOAA Climate Prediction Center Seasonal Drought Outlook (http://droughtmonitor.unl.edu) may be used to enhance producers' decision-making. However, inserting additional information into the decision-making process does not guarantee effective use of that information. Rather, research has found a significant gap between information provision and information use $[5,6]$. The realization of successful drought early warning, therefore, lies as much with the potential users as with the providers of monitoring information. It requires (1) that the information will be accessed and understood by decision-makers; (2) that decision-makers will use the information to make timely and effective coping and adaptation decisions as a result of incorporating the information; and (3) that the decisions made will result in fewer, or less severe, impacts (harm or loss) due to drought $[7,8]$.

The integration of drought early warning into rangeland managers' coping and adaptive decision-making requires an understanding of the complexity of livestock-rangeland systems and drought response options [9]. Decision-making in agricultural systems is complex even before drought begins to emerge. Rangeland managers act within multifaceted, 
interconnected socioecological systems that encompass rangeland ecosystems, livestock production, markets, and business and family systems [10]. Their decision-making todo lists includes tasks that need to be carried out in the next few days, over the coming weeks or months, as well as into future seasons or years [11]. When a drought event occurs, range and livestock managers' responses are varied in type, scope, and timing [12-15]. While some managers make incremental modifications to their management in response to drought, others act in ways that may transform their operations for the long term; and while some focus on on-farm responses, others may hope for off-farm (governmental) assistance. Managers' decisions to take actions-proactively before drought emerges, concurrently as it emerges, and/or responsively after drought has clearly taken hold-are likely to have unique outcomes in terms of impacts to the socioecological system [16]. Yet, there is little documentation of the outcomes of proactive, concurrent, and responsive decisionmaking in rangeland-based livestock systems or the timing of decision-making that might classify an action as proactive versus responsive.

The timing of decision-making is a critical, yet understudied, aspect of drought early warning [17]. In some regions of the world, the timing of response is of concern because of the risk of emergent food insecurity or even famine [18]. In these instances, the timing of agricultural producers' response to drought may provide cues to relief agencies as to how quickly relief may be needed [19]. In the U.S. Great Plains, drought has not been associated with famine. However, the timing of producers' responses, as much as what their responses are, affects the long-term ecological health of grasslands and croplands, water supplies, agricultural markets, farm economics, and the health of decision-makers, families, and communities [20, 21]. Despite the importance of the timing of response, little is known about how agricultural producers make their decisions to begin a drought response action, or the degree to which drought monitoring information is used to trigger the beginning the response.

\section{Conceptual Framework}

The use of early warning information in coping and adaptation is a focus of a body of research in short-term emergency responses to fires, hurricanes, and other disasters. One prominent guiding theoretical model, the Protective Action Decision Model (PADM) [22], locates the role of early warning information in a social-psychological process of decision-making in response to hazards. Specifically, warnings are seen as cues to action that inform an individual's processes of perceiving and comprehending the nature of the threat $[22,23]$. Warnings include all sources of information that convey a threat, commonly communicated through the media, alarms, presentations, or decision tools [24]. Cues to action may also come from the natural or social environment [22]. For the range-based livestock manager, for example, deviations from normal in precipitation or forage growth may be natural environmental cues that a drought threat is at hand. Social cues may come in the form of heightened awareness due to observations of increased sales at the livestock barn or increases in local forage prices.

The existence of a cue does not itself spontaneously lead to an individual taking protective action. Rather, the individual must observe, pay attention to, and comprehend the cue, then establish that the cue represents enough of a personal risk to necessitate taking action, and finally identify and choose among options for response [22]. Individuals who process and move through these stages quickly may take protective action earlier than those who spend more time addressing uncertainty and processing information $[25,26]$. Thus, examining drought coping response within this framework may lead to better understanding of the drivers of proactive and responsive or reactive coping actions [16].

Drought is a notoriously difficult natural hazard to perceive, adding to the uncertainty and complexity of decisionmaking [27]. In complex decision-making environments, managers may encounter multiple and conflicting types of cues to action. Environmental and social cues may be asynchronous or contradict one another. Sources of warning may not provide consistent messages of the nature or severity of the threat. And warnings may differ in timing, precision, visibility, message specificity to the audience, and other characteristics that have been summarized by Cash et al. [28] as information salience, credibility, and legitimacy and by Lemos et al. [5] as the perceived fit, interplay, and interaction of the information by decision-makers. A better understanding of the choices and timing of rangeland managers' drought coping responses in the context of environmental, social, and early warning cues will enable information providers, risk communicators, and educators/advisors to more effectively provide information that meets decision-maker needs.

\section{Materials and Methods}

3.1. Selection of the Study Area. This study investigates the triggers of drought response and examines the role of early warning information in timely drought response decisionmaking. To do so, U.S. Northern Great Plains livestock producers were surveyed about their coping decisions (related to feed, forage, and grazing pressure) in response to a 2016 flash drought. As reported in Otkin et al. [29], the 2016 drought event developed by the end of March, in response to a prolonged period of warmer than normal temperatures and near- to below-normal precipitation during the preceding fall and winter. April brought wetter conditions to much of the region, but by the end of May, very dry conditions returned to most of the region, and temperatures were also much cooler than normal. Several hard freezes occurred across the region, heavily damaging the vegetation in some locations. In June, rapid drought intensification occurred, with much warmer than normal temperatures and continued below-normal precipitation and drought intensity peaked across the region by the middle of July. Precipitation began normalizing toward the end of August.

The drought event affected parts of a four-state region including portions of South Dakota, Wyoming, Nebraska, and Montana. Livestock production in the study region is dominated by cow-calf enterprises that depend upon local 
rangelands as well as regional supplies of hay and feed. The predominant land cover of the region ranges from tall-grass to short-grass prairie and contains mixed shrub/grassland, forage, wheat, corn, and sugar beet-producing cropland, and forestland. The area is largely dependent upon precipitation for agricultural production, with limited areas of irrigated cropland (https://earlywarning.usgs.gov/images/usewem/ 2012_MIrAD_CONUS.png). In 2016, the primarily rural region experienced drought impacts such as forest and grassland fires, reductions in grain yields, reduced forage production, water quality and quantity problems, and economic losses [30]. Economic losses may have been compounded by low prices for feeder cattle, while also somewhat alleviated by plentiful hay stocks nationally and locally [31]. These characteristics make the area and drought event appropriate for studying rangeland managers' drought response and use of drought monitoring/early warning information.

3.2. Sampling Design and Survey Instrument. Livestock producers were identified through a Farm Services Agency list of agricultural landowning households with a history of production forage, wheat, corn, or sugar beets, whose addresses place them within the study region. The sample was stratified based on the location of their addresses in relation to the 2016 drought's extent and severity. Four strata were defined by the U.S. Drought Monitor (USDM) severity level (D0, D1, D2, and D3) of the landowner's county in mid-July 2016 (representing the greatest severity and geographic extent of the drought event) (Figure 1). The USDM is a composite measure of drought stress [4] used to depict abnormally dry conditions (D0) and four drought categories including moderate (D1), severe (D2), extreme (D3), and exceptional (D4) drought. In order to ensure representation of landowners experiencing all four levels of drought severity, landowners living in USDM D0 and D1 strata (which happened to include more highly populated counties) were undersampled, while landowners living in USDM D2 and D3 strata (which happened to include less populated counties) were oversampled.

The survey was administered by the National Drought Mitigation Center via the U.S. Postal Service following the Dillman [32] protocol, with a presurvey letter mailed in early November 2016, an initial survey mailing in late November 2016, and a follow-up survey mailing in early January 2017. Of the 2,389 surveys that were mailed out, 516 (22\%) were returned/not refused. Of these, 252 were received from eligible agricultural producers who reported raising livestock and used in this analysis.

The survey instrument was developed with the input of content and theory experts and pretested with agricultural extension personnel volunteers. The questionnaire focused on the 2016 drought and included questions about timing of drought-related conditions as observed by the respondents, the types and timing of drought management actions that they took, the types and influence of drought monitoring information they used, and the impacts they experienced. Specific question wording is listed in Appendix A. Measures of outcome variables included

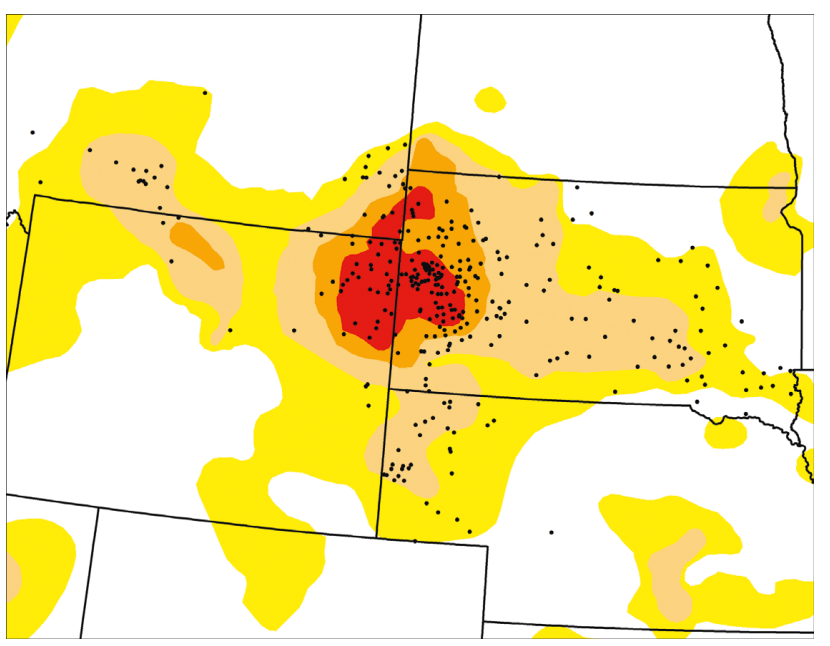

FIgURE 1: Points represent the approximate locations of survey respondents and are randomly distributed within respondents' zip codes, to protect individual identities. The colors on the map represent the U.S. Drought Monitor designation as of July 26, 2016, with yellow indicating abnormal dryness, tan indicating moderate drought, orange indicating severe drought, and red indicting extreme drought.

(i) Whether or not respondents took any of the following actions in response to drought: purchasing more hay or feed than usual to supplement existing feed stocks; grazing fall or winter pastures earlier than planned; destocking pastures more than usual through culling, early weaning, ending grazing contracts, sending to feedlot, etc. of any livestock; and culling and selling more breeding animals, specifically, than usual. If a respondent took none of the listed actions in 2016, they were considered to have not responded to the drought for the sake of this analysis.

(ii) If the respondent took action in any of the ways listed above, in what month they began doing so (January-December 2016). Respondents who did not take an action were listed as missing for this variable.

(iii) The respondent-reported impacts of the 2016 drought, by percentage of yield or productivity lost $(0-100 \%)$, on each of the following: pasture hay yield; range productivity; range health or diversity; animal gain/productivity; net income of the operation; and cash reserves or savings.

(iv) Respondents' perceptions as to whether better information would have led them to respond differently and whether responding differently would have led to different impacts.

Measures of predictor variables included

(i) Respondents' observations of various conditions related to drought and the timing of the observations, including decreased topsoil moisture; delayed/lack of plant emergence; delayed/lack of plant growth; deteriorating range conditions; and 
decreased forage productivity. For respondents who reported not observing a condition at all, their date of observing the condition was reported as 366, rather than as missing.

(ii) Respondents' use and perceived influence of their own methods of monitoring drought, including on-farm rain gauges or soil moisture sensors and/or their own assessment of crop, range, and livestock conditions. Respondents not using a source were coded as " 0 " while respondents using were coded as the level of influence from " 1 " (not influential) to " 3 " (very influential).

(iii) Respondents' use and perceived influence of external sources of drought monitoring or early warning information, including local extension, the U.S. Department of Agriculture, National Weather Service, and the U.S. Drought Monitor. These sources were chosen as known sources of weekly, monthly, and seasonal drought monitoring and/or outlook products and information. The U.S. Drought Monitor (https://www. droughtmonitor.unl.edu) is released weekly throughout the year and is featured by news media outlets, included in extension and USDA publications, shared via social media, and accessed online. The Climate Prediction Center provides temperature and precipitation outlooks and monthly and seasonal drought outlooks (http:// www.weather.gov). The USDA provides a Weekly Weather and Crop Bulletin (https://www.usda.gov/oce/ weather/pubs/Weekly/Wwcb/), and local extension offices provide drought information to producers through reports and presentations (https://drought. unl.edu/archive/Documents/NDMC/Workshops/795/ Pres/Edwards-SD2016USDM.pdf). Respondents not using a source were coded as " 0 " while respondents using were coded as the level of influence from " 1 " (not influential) to " 3 " (very influential).

Specific research hypotheses evaluated during this study included

(1) The decision whether or not to take drought response actions is predicted by

(a) Drought severity experienced

(b) Respondents' observation of drought conditions, and/or

(c) Respondents' use and influence of their own monitoring or external early warning information

(2) The timing of respondents' drought response actions is predicted by

(a) Drought severity experienced

(b) The timing of respondents' observation of drought conditions, and/or

(c) Respondents' use and influence of their own monitoring/assessments or external early warning information

(3) Respondents who are delayed in their actions experience drought impacts differently from those who acted earlier
3.3. Measures of Drought Emergence and Severity. Multiple measures of drought emergence and severity were examined throughout the analysis, as measures of environmental cues to action and as a control variable for determining statistical relationships. The median 3-month Standardized Precipitation Evapotranspiration Index (SPEI) for the months of October 2015 through June 2016 was used to represent measures of the overall dryness experienced by each survey respondent during the months that drive forage productivity in the region [33]. The 3-month SPEI depicts the balance between precipitation and potential evapotranspiration over the previous 3 months, calculated at weekly intervals [3]. County-level weighted averages were computed using station-based historical data that were interpolated using inverse distance weighting.

Other indicators of drought were examined because of their direct relationship with our measures of respondentperceived drought conditions. The North American Land Data Assimilation System topsoil and total column moisture (NLDAS TS and TC) provide model-based objective measures of topsoil and subsoil moisture that correlate with respondent-perceived emergence of depleted topsoil and subsoil moisture. These measures are based on models that simulate changes in soil moisture and temperature throughout layers of the soil profile [29]. For this analysis, gridded soil moisture analyses were obtained from NLDAS at 0.1258 degree resolution [34], with soil moisture anomalies computed over 4-week time periods using data from 1979-2017. Ensemble mean analyses were used for topsoil (TS; $0-10 \mathrm{~cm}$ ) and total column (TC; $0-2 \mathrm{~m}$ ) soil moisture measures. Each dataset was aggregated to the zip code level for the study region. As reported in Otkin et al. [29], respondents' recollection of the timing of top soil moisture depletion generally aligned with drought development as indicted by NLDAS TS.

The Evaporative Stress Index (ESI) was examined to depict moisture-related stress in vegetation, both related to vegetation health and to soil moisture availability [35]. The ESI depicts standardized anomalies in the ratio of actual to reference evapotranspiration, and deteriorating conditions as measured by ESI have been shown to correspond with the timing of respondent reports of plant stress [29]. For this analysis, the ESI was computed at $4 \mathrm{~km}$ horizontal grid spacing, with 4 week ESI anomalies at weekly intervals using data from 2001 to 2017 [29, 35]. Each dataset was aggregated to the zip code level for the study region.

3.4. Time Series Comparisons. The relationships between the emergence and development of drought conditions and the timing of drought response actions were examined through a novel method introduced by Otkin et al. [29]. The relationships between drought response action timing and the associated 4 week ESI, NLDAS TS, and NLDAS TC trends were quantified by averaging each dataset over all zip codes during a 12 week period centered on the date that each response action was first taken (week zero). For a given zip code, a shape file was used to identify all of the grid points on 
the 4-km resolution grid located within that zip code. Values for these grid points were then used to compute the mean for each dataset. An average time series for each survey question and dataset was then generated using the recentered time series from all respondents who responded with a month that they began taking drought response actions. These recentered time series were used to evaluate relationships between the timing of the reported management actions and the timing of drought development in the drought monitoring datasets. Recentering the time series for each response prior to computing the average time series promotes a more robust comparison of the datasets because the differential timing of drought development across the region is included in the measure.

3.5. Statistical Analysis. Testing the hypotheses and identifying factors that predict actions taken, the timing of actions, and drought impacts required controlling for average drought severity. Regression models were used to estimate the coefficient of predictive variables with the control variable in the model. Predictors of whether or not drought response actions were taken, as binary categorical outcomes, were examined using logistic regression models. Predictors of the month respondents began taking action, as ordinal categorical outcomes, were examined using ordered logistic regressions (proportional odds models [36]). Predictors of integer variables, including the date of observed drought conditions, as well the percent loss impact of drought, were examined using linear regression models. Logical skippatterns in data led to substantial missing data for some variables. Cases with missing data were eliminated from analysis using pairwise deletion. Data were unweighted, but stratification was accounted for in the analysis using the STATA "svy" method (STATA v. 11) [37]. Statistical significance was determined with a $95 \%$ confidence level at an alpha $=0.05$.

\section{Results and Discussion}

4.1. Description of Respondents and Drought Response. Respondents almost all raised beef cattle, owned and ranted/ leased a mean land base of 1,983 ha (range 16 ha-15,176 ha), and had gross sales ranging from less than $\$ 25,000$ to more than $\$ 500,000$ annually. Consistent with the sampling frame, all respondents lived in areas that experienced some level of dryness in 2016, ranging from abnormal dryness to extreme drought. Some respondents began observing drought conditions as early as the winter of 2015-2016, but most reported seeing early indications of dryness (decreased topsoil moisture and/or delayed or lack of plant emergence) in May. The most frequently reported month for beginning to observe decreased subsoil moisture, delayed/lack of plant growth, and/or decreased forage productivity was June. The most frequently reported month for beginning to observe deteriorating range conditions was July. Descriptive statistics for all predictor and outcome variables can be found in Table 1.
In response to the drought, respondents took a number of coping actions and varied in the timing of their actions. Figure 2 shows the timeline of actions taken. Two-thirds of respondents grazed fall or winter pastures early, primarily in August and September 2016. Over half of respondents destocked their pastures more than usual due to drought, through any culling, early weaning, ending grazing contracts, or sending livestock to feedlots. While some respondents began destocking as early as May or June, most waited to begin destocking until September 2016. Of the 57\% of respondents who purchased supplemental hay or feed in 2016, some began in early summer but most waited to begin purchasing until October 2016. Similarly, of the $46 \%$ of respondents who culled their breeding herd, the peak month for beginning that particular action was October 2016. Most respondents used multiple response strategies. Respondents who used both early grazing fall/winter pastures and destocking as drought response strategies tended to begin destocking later in the season compared to those who destocked but did not early graze fall/winter pastures. Other actions did not affect the timing of one another.

In terms of drought monitoring and early warning information, respondents were more likely to use and be influenced by their own on-farm monitoring or assessments of drought conditions than any external source of early warning information. Of the external sources of monitoring/ drought early warning information listed, respondents perceived the National Weather Service to be the most influential to their farm management during drought and local Extension information to be the least influential. Other sources, including the U.S. Drought Monitor and resources provided by the U.S. Department of Agriculture, fell towards the middle.

4.2. Factors Affecting Respondents' Drought Response. Approximately $87 \%$ of respondents reported taking some type of management action in response to drought conditions. Table 2 lists the log-odds coefficients of variables used to predict the likelihood of respondents' taking action, controlling for the median 3-month SPEI. Respondents who observed delayed or lack of plant emergence or growth, decreased forage production, and/or deteriorated range conditions, even controlling for drought severity (SPEI), were more likely than others to purchase supplemental hay or feed, graze fall/winter pastures earlier than usual, destock any livestock more than usual, and/or reduce the size of breeding herds. The degree to which managers used and were influenced by USDA resources was also associated with the likelihood of culling the breeding herd, regardless of drought severity. The $13 \%$ of the respondents in this study who did not take any of the listed actions experienced significantly less dryness over the October 2015-June 2016 timeframe than did the rest of the sample and were less likely than others to observe any drought-related conditions. These findings support hypothesis 1 , providing some evidence that respondents' use and influence of early warning information contributed to their perceptions of personal risk and 
TABle 1: Descriptive statistics.

\begin{tabular}{lc}
\hline Operation characteristics & Proportions or means $(n)$ \\
\hline Types of livestock produced & Beef cattle-97\% $(n=237)$ \\
\hline Total hectares & Mean $1,893($ SE 2,369$)(n=234)$ \\
\hline & $<25,000-10$ \\
Operation gross sales $(\$)$ & $25,000-99,999-30 \%$ \\
& $100,000-249,000-33 \%$ \\
& $250,000-499,999-17 \%$ \\
\hline
\end{tabular}

On-farm rain gauge $(n=237)$, mean $=1.58($ SD 1.19)

Own assessment $(n=234)$, mean $=2.13($ SD 1.17)

Local extension resources $(n=236)$, mean $=0.60$ (SD 0.95)

Use and influence of drought monitoring

National weather service $(n=235)$, mean $=1.60$ information (SD1.08)

U.S. drought monitor $(n=236)$, mean $=1.23$ (SD 1.15)

USDA resources $(n=232)$, mean $=0.88($ SD 1.08)

Television/radio reports $(n=234)$, mean $=1.69$ (SD 0.98)

Average 3-month SPEI between October 2015 and June 2016 experienced by respondents

Conditions observed by respondents

Mean $=-0.10($ SD 0.26), with a range of -0.60 to 0.57 $(n=246)$

Decreased topsoil moisture $(n=250)-96 \%$, May (mode)

Delayed or lack of plant emergence $(n=225)-74 \%$, May

Decreased subsoil moisture $(n=239)-96 \%$, June

Delayed or lack of plant growth $(n=243)-91 \%$, June

Decreased forage productivity $(n=235)-94 \%$, June

Deteriorating range conditions $(=n 235)-94 \%$, July

Graze fall or winter pastures earlier than planned $(n=228), 68 \%$, Sept

Destock pastures more than usual $(n=224), 56 \%$, Sept

Actions taken and mode month

Purchase more supplemental hay/feed than usual $(n=224), 57 \%$, Oct

Cull and sell more breeding animals than usual $(n=221), 47 \%$, Oct

Took none of these actions $(n=235), 14 \%$ N/A

Pasture hay yield $(n=197), 65.76 \%(31.86)$

Range productivity $(n=180), 49.17 \%(24.72)$

Range health or diversity $(n=134), 38.31 \%(30.37)$

Animal gain or productivity $(n=158), 12.18 \%$ (16.68)

Net income of operation $(n=196), 32.52 \%(22.50)$

Cash reserves or savings $(n=151), 25.15 \%(26.27)$

Would have acted earlier or differently, given earlier warning

Would have seen less harm, given different/earlier action

Data sources: 2016 survey, SPEI (droughtatlas.unl.edu).

influenced their decisions to take at least one of the actions, as predicted by the PADM [22].

\subsection{Factors Affecting the Timing of Respondents' Drought} Response. On average, managers did not begin responding to the drought until the fall of 2016, even if drought was severe months earlier. Average dryness, as measured by the 3-month SPEI, between October 2015 and June 2016 was useful for predicting the start of early grazing, with more severe drought associated with earlier start dates. SPEI did not predict the timing of other actions. Table 2 lists the logodds coefficients of other variables used to predict the timing of respondents' actions, controlling for the median 3-month SPEI. The timing of respondents' observations of emerging drought conditions was statistically unrelated to the timing of actions, with one exception: the timing of observation of 


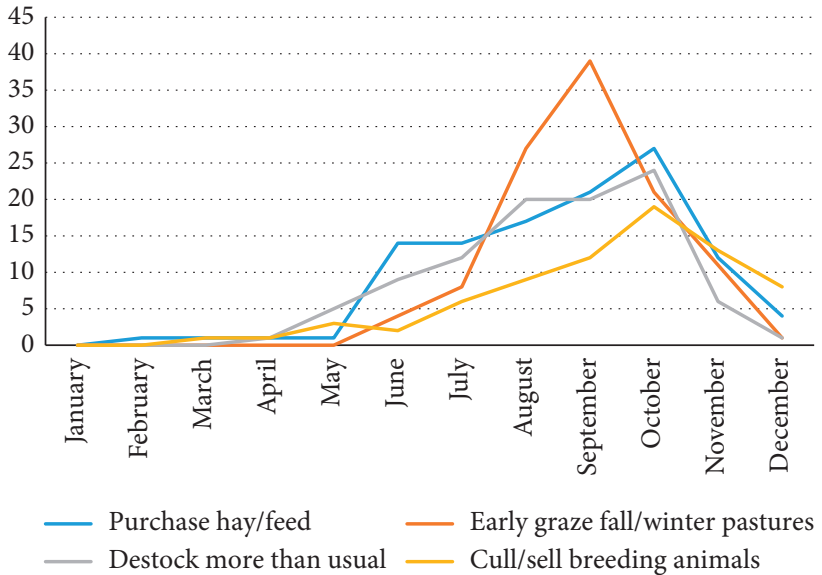

FIGURE 2: Number of respondents who took each action in response to drought conditions in 2016 by month.

delayed plant emergence was negatively correlated with the timing of destocking pastures. In other words, respondents who observed delayed plant emergence earlier in the year reported later destocking dates than those who observed the condition later or not at all, which is the opposite of the expected relationship predicted by the PADM model.

In general, respondents observed conditions that indicated the development of drought well in advance of taking drought response actions. While respondents' observations of on-the-ground drought conditions were largely synchronous with the development of the drought as measured by NLDAS TS, NLDAS TC, and ESI (as reported in Otkin et al. [29]), the timing of their drought response actions was not. Figures 3 and 4 demonstrate the relationships between objective drought measures and respondents' observations and the lack of relationships with respondents' actions. Figure 3 shows the average trends in the three measures in relation to the date of respondents' first observations (week 0) of decreased topsoil moisture, delayed/lack of plant emergence, delayed/lack of plant growth, plant stress, deteriorating range conditions, and decreased forage productivity. In all cases, on average, NLDAS TS, NLDAS TC, and ESI indicated the emergence and increased severity of drought in time with respondents' observations. Each time series shows a downward trend from normal conditions to drought (falling below -0.5 on each mean standardized anomaly).

Analysis of the trends in the emergence and development of the drought, as measured by NLDAS TS, NLDAS TC, and ESI, demonstrates the lack of relationship between the timing of the emergence of drought and the timing of drought response (Figure 4). Whereas drought-related conditions were observed in time with increasing deviation from normal in soil moisture or evaporative stress, the drought response actions began (on average) during either an upward trend or no trend in drought indices. Time series lines that show neither an upward nor a downward trend indicate either stable conditions or no trend in drought conditions on average. Time series lines showing an upward trend indicate that drought conditions (as measured by these indices) were generally improving by the time the action was taken, on average.
A return to normal conditions does not imply that drought impacts have disappeared or that drought management actions are not necessary. ESI, for example, may show improvements with late-season green-up that do not necessarily indicate adequate forage availability [17]. It has been demonstrated that, for the study region, precipitation over the winter months and spring is a critical determinant of forage productivity during the summer [33]. In western South Dakota, over $60 \%$ of annual forage production occurs by July 1 and $90 \%$ by August 15, while in eastern Montana, $90 \%$ of annual forage production occurs by July 1 [38]. Grazing preferred forages during late-season green-up after drought is generally not recommended, as it can damage the following years' production (https://hayandforage.com/article1253-recovering-pastures-after-a-drought.html; https:// newsroom.unl.edu/announce/beef/6982/39981; https://www. ag.ndsu.edu/archive/dickinso/grassland/news/news5.htm; https://www.drovers.com/article/grazing-considerations-dr). Thus, respondents were likely respondent to observed drought impacts when they chose to take action, rather than responding to leading indicators of drought emergence and development. These results provide only weak support for hypotheses 2(a) and $2(b)$.

There is some evidence that respondents who conducted their own on-farm monitoring or other assessments of local conditions timed their drought response actions differently from others, providing some support for hypothesis 2(c). First, respondents who said that their own assessments of conditions were influential in their decision-making reported earlier observations of decreased topsoil moisture (Table 3) and also tended to destock earlier than those who did not (significant at 0.10 ). This relationship with the timing of destocking, while only marginally significant, is in the direction that would be expected theoretically. It is possible that managers who assessed conditions throughout the drought were somewhat faster in determining that drought posed a risk to them and deciding that action needed to be taken sooner rather than later, as would be predicted by the PADM [22]. However, another relationship between monitoring and the timing of action is in the opposite direction. Respondents who said that their on-farm monitoring (rain gauge or soil moisture sensors) was influential 


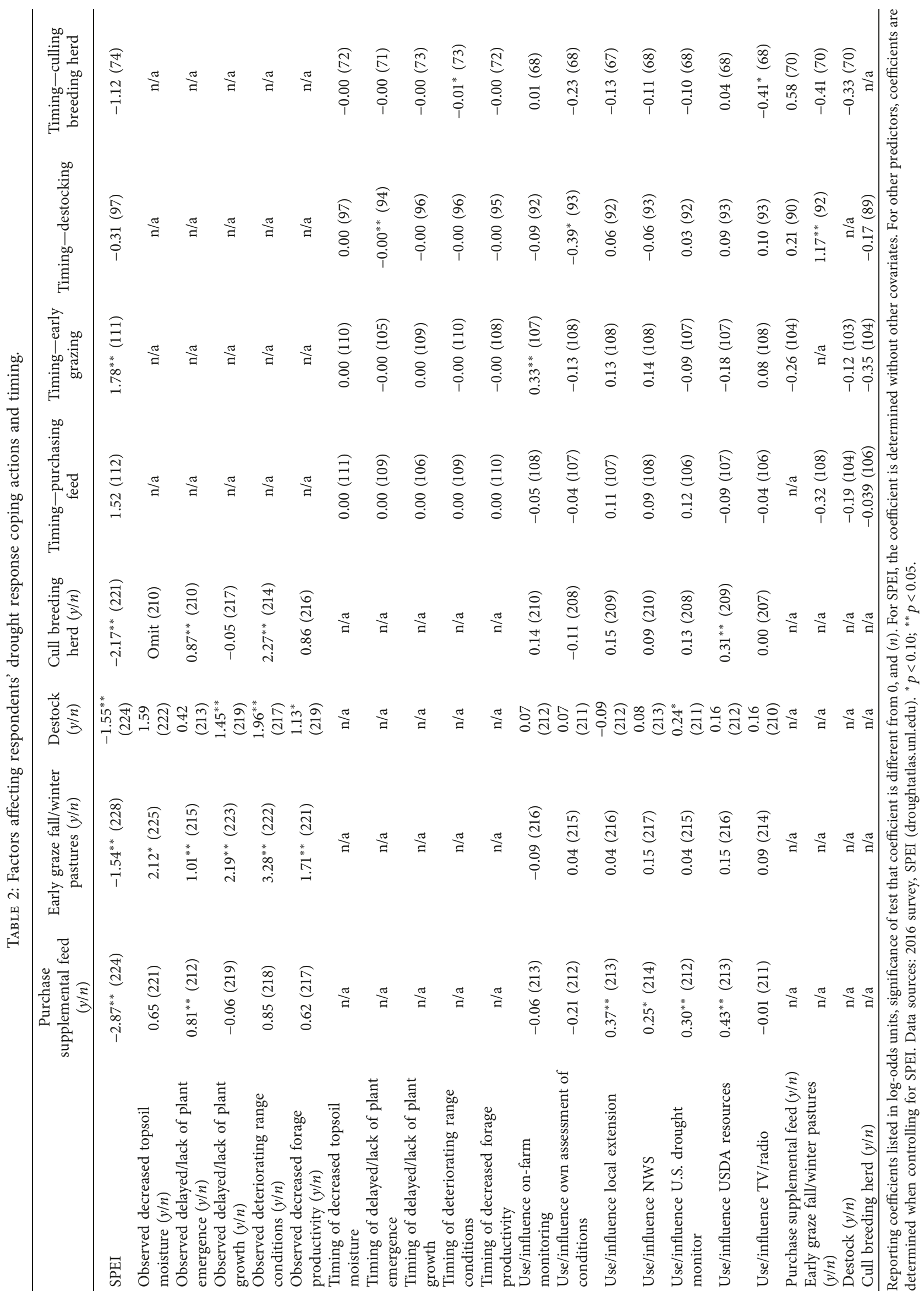




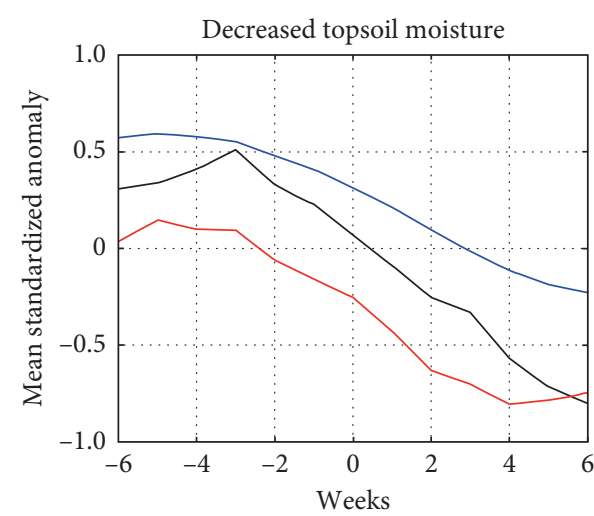

(a)

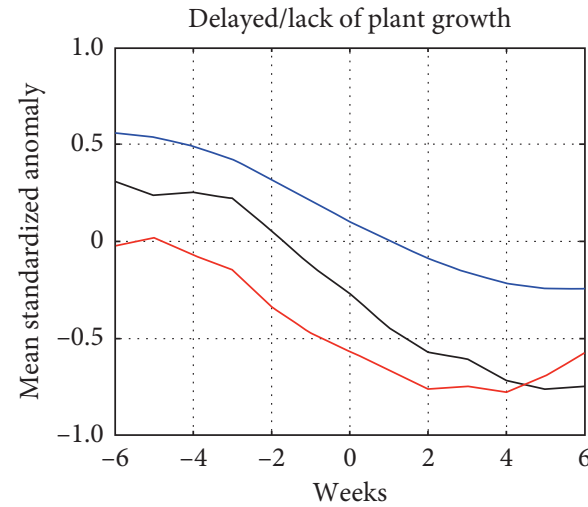

(c)



(e)

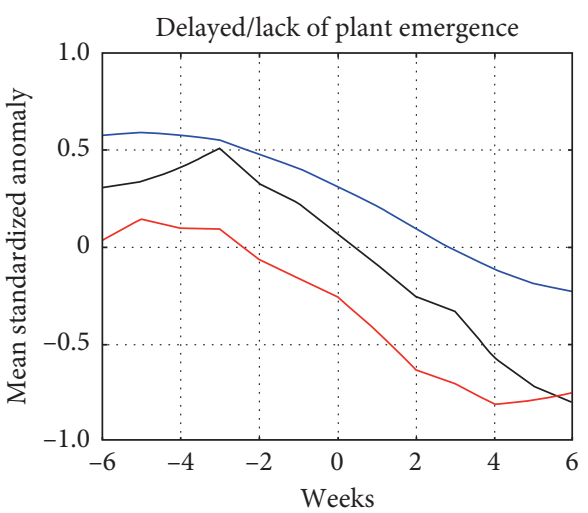

(b)

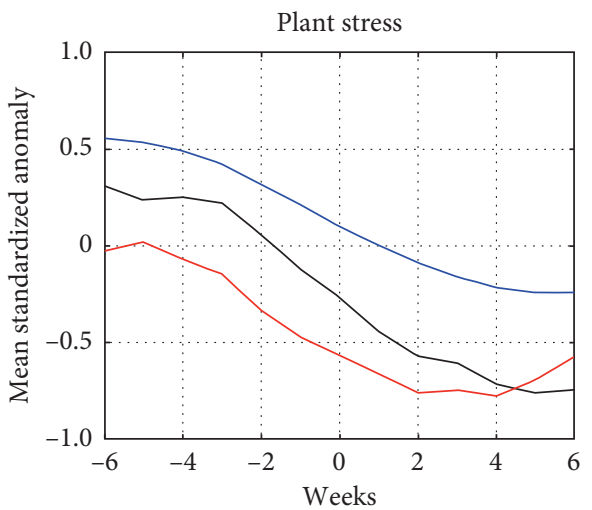

(d)

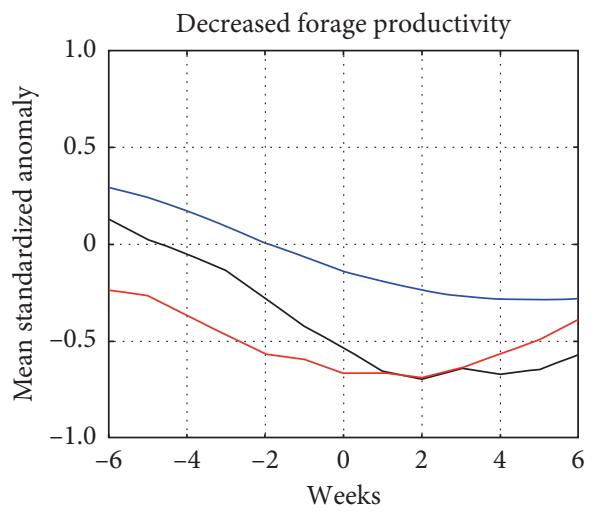

(f)

FIGURE 3: Time series showing the average condition depicted by anomalies in the ESI (black line) NLDAS TS (red line) and NLDAS TS (blue line) data sets at weekly intervals from six weeks prior to six weeks after the onset: (a) decreased topsoil moisture, (b) delayed/lack of plant emergence, (c) delayed/lack of plant growth, (d) plant stress, (e) deteriorating range conditions, and (f) decreased forage productivity as reported by the respondents.

tended to begin grazing fall/winter pastures later than others did, even though more severe SPEI predicted earlier fall/ winter grazing. Using the PADM framework, this may indicate that managers using on-farm rain gauges or soil moisture sensors were later than others to determine the need for protective action in the form of early grazing fall/ winter pastures or decided that later action was desirable. One possibility is that managers who used on farm monitoring were more likely than others to be able to reserve fall/ winter pastures for their intended purpose, rather than as an emergency feed source. Other covariates not included in this analysis may be necessary to explain the relationship.

The degree to which respondents used and were influenced by external sources of early warning information did not predict the timing of respondents' drought actions, providing lack of support for hypothesis 2(c). That is not to say that drought early warning had no effect on respondents at all. Increased use/influence of multiple sources of drought early warning information was associated with earlier observations of delayed/lack of plant growth and decrease 


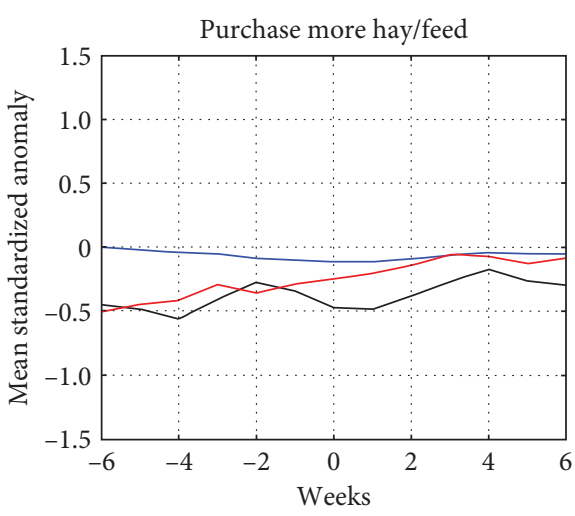

(a)

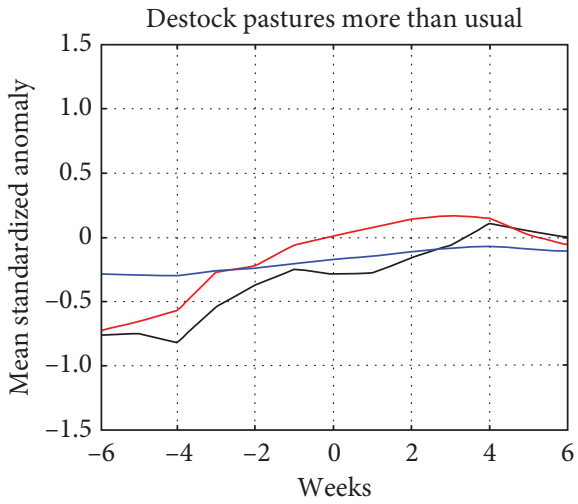

(c)

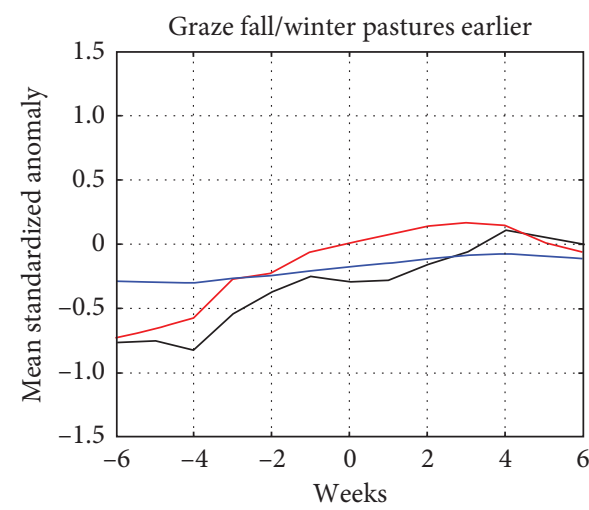

(b)

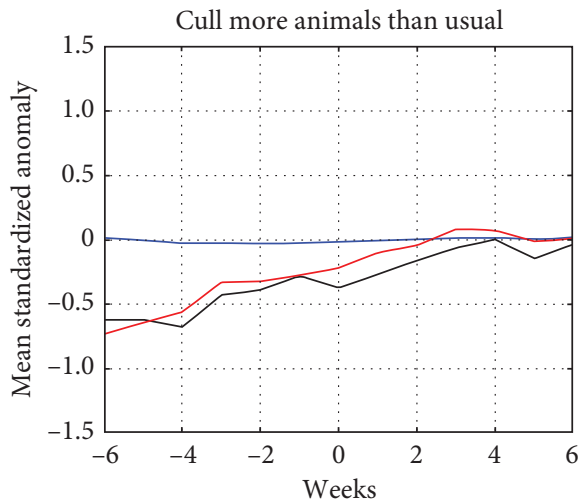

(d)

FIgURE 4: Time series showing the average condition depicted by anomalies in the ESI (black line) NLDAS TS (red line) and NLDAS TS (blue line) data sets at weekly intervals from six weeks prior to six weeks after the average beginning of drought response actions, including (a) purchasing more hay or feed than usual, (b) grazing fall/winter pastures earlier than usual, (c) destocking pastures more than usual, and (d) culling more breeding animals than usual.

forage productivity (Table 3). However, just as the timing of observing these drought conditions was unrelated with the timing of action, so was the use and influence of drought early warning information. These findings indicate that while drought early warning is perceived and understood by managers as an alert about deteriorating conditions, it is not currently being perceived by managers as a primary cue to take action.

External sources of uncertainty may slow managers' decision-making processes about drought response. Managers may not immediately be able to determine what the financial or other implications of their actions could be, as markets for their supplies and products change and as policy responses are announced expectedly or unexpectedly [39]. For example, farm commodity (including corn, soy, and wheat) and livestock prices had been on a downward trend throughout 2016 (https://www.bloomberg.com/graphics/ 2016-farm-economy/), which may have affected decisions that weighed purchasing feed against destocking livestock. Further, administration of the USDA Livestock Forage Disaster Program (LFP) may have played a role in the timing of drought response. As legislated in the 2014 Farm Bill (https://www.fsa.usda.gov/Assets/USDA-FSA-Public/usda files/FactSheets/archived-fact-sheets/2016_livestock_for age_disaster_program.pdf), producers who live in counties that meet conditions triggered by the U.S. Drought Monitor automatically become eligible to apply for LFP, but the amount a producer will be eligible to receive depends upon both drought intensity and length of time in drought. The promise of an LFP payout may lessen a manager's feeling at risk of running out of feed due to drought because they will have financial assistance for purchasing feed for livestock if the drought continues. This possibility may lead some to wait until later in the year to decide whether they will actually need to destock.

4.4. Factors Affecting Drought Impacts. Individuals varied in the losses that they experienced as a result of the 2016 drought event. On average, the largest percentage losses were to pasture hay yield and range productivity and the smallest percentage losses were to livestock gain/productivity (Table 1). Table 4 lists the coefficients of variables used to predict the percent loss, controlling for the 3-month SPEI. When controlling for drought severity, the timing of action was useful in predicting some impacts, providing support for hypothesis 3 . The timing of destocking was related to the percentage loss of range productivity and to range health and diversity, with those destocking later reporting higher losses. Holding 3-month SPEI constant, for every month later that 
TABLE 3: Factors affecting the timing of observed conditions.

\begin{tabular}{|c|c|c|c|c|c|}
\hline & $\begin{array}{l}\text { Timing decreased } \\
\text { topsoil moisture }\end{array}$ & $\begin{array}{l}\text { Timing delayed/lack } \\
\text { of plant emergence }\end{array}$ & $\begin{array}{c}\text { Timing delayed/lack } \\
\text { of plant growth }\end{array}$ & $\begin{array}{c}\text { Timing deteriorating } \\
\text { range conditions }\end{array}$ & $\begin{array}{l}\text { Timing decreased } \\
\text { forage productivity }\end{array}$ \\
\hline SPEI & $102.27^{* *}(250)$ & $122.14^{* *}(239)$ & $139.72^{* *}(248)$ & $113.26^{* *}(242)$ & $90.03^{* *}(243)$ \\
\hline $\begin{array}{l}\text { Use/influence on-farm } \\
\text { monitoring }\end{array}$ & $-3.80(237)$ & $8.40(227)$ & $-3.58(236)$ & $-2.67(230)$ & $0.51(231)$ \\
\hline $\begin{array}{l}\text { Use/influence own } \\
\text { assessment of conditions }\end{array}$ & $-8.38^{* *}(236)$ & $-3.00(225)$ & $-6.66(234)$ & $-7.99^{*}(229)$ & $-5.56(229)$ \\
\hline $\begin{array}{l}\text { Use/influence local } \\
\text { extension }\end{array}$ & $3.93(237)$ & $2.76(226)$ & $-8.48^{* *}(235)$ & $5.39(230)$ & $3.29(230)$ \\
\hline Use/influence NWS & $1.33(238)$ & $-7.48(227)$ & $-6.51^{*}(236)$ & $-5.54(231)$ & $-11.84^{* *}(231)$ \\
\hline $\begin{array}{l}\text { Use/influence U.S. } \\
\text { drought monitor }\end{array}$ & $-0.73(236)$ & $-5.98(225)$ & $-4.74(234)$ & $-3.21(229)$ & $-4.90(229)$ \\
\hline $\begin{array}{l}\text { Use/influence USDA } \\
\text { resources }\end{array}$ & $-1.13(237)$ & $-10.72(226)$ & $-12.03^{* *}(235)$ & $-2.12(230)$ & $-1.80(230)$ \\
\hline Use/influence TV/radio & $2.39(235)$ & $-4.64(224)$ & $-8.18^{* *}(233)$ & $1.73(228)$ & $-1.35(228)$ \\
\hline
\end{tabular}

Reporting coefficients, significance of test that coefficient is different from 0 , and $(n)$. For SPEI, the coefficient is determined without other covariates. For other predictors, coefficients are determined when controlling for SPEI. Data sources: 2016 survey, SPEI (droughtatlas.unl.edu). ${ }^{*} p<0.10 ;{ }^{* *} p<0.05$.

respondents began destocking, they reported an additional $3.49 \%$ loss to range productivity and an additional $4.78 \%$ loss to range health/diversity. Timing of destocking was related to loss of range productivity even when holding the earlygrazing-of-fall/winter-pastures $(y / n)$ variable constant. This study provides evidence that livestock producers are continuing to see negative impacts to herbage production and range health and diversity, in part due to failure to decrease grazing pressure early enough in the season. While some researchers report increased drought preparedness among rangeland managers [13], this study would indicate that there continues to be room for improvement in timely decision-making.

Later actions were not always associated with greater losses, however. The timing of buying supplemental feed was correlated with loss of cash reserves or savings and loss of animal gain or productivity-those who started purchasing supplemental feed later in the year also experienced less loss to their savings and animal gain. For every month later in 2016 that respondents began buying supplemental feed, they experienced $5.10 \%$ less loss to their cash reserves or savings and $2.11 \%$ less loss to their animal gain/productivity (Table 4). Unlike the effect of delayed destocking on rangeland health, there may not be harm in waiting to purchase supplemental hay or feed, as long as local supplies remain available and affordable. In 2016, national hay supplies were plentiful, though local hay prices did increase starting in July in response to local demand (https://www.ams.usda.gov/ market-news/hay-reports). While those who waited until later in the year were likely to pay slightly more for hay than those who purchased earlier in the year, if they were purchasing for a fewer number of months than those who began purchasing earlier, they may still have benefitted economically. However, other drought events may be geographically more widespread or coincide temporally with high hay and feed prices, which would make waiting to purchase supplemental hay/feed a gamble.

After the 2016 drought event, approximately $28 \%$ of all respondents said that they would have acted earlier or differently if they had had information earlier that drought was emerging, and $25 \%$ of respondents said they thought they would have seen less harm had they acted earlier or differently. The timing of drought response actions was useful in predicting whether they had regrets after the drought (Table 5). Respondents who began destocking later in the year were more likely than others to say that they would have seen less harm to their operations if they had acted earlier or differently, controlling for SPEI. This relationship aligns with the correlation between later destocking and increased harm to rangeland resources. Respondents who used on-farm monitoring and/or NWS early warning were more likely than others to say that they would have taken action earlier or differently with earlier warning of drought. These results support prior research finding that producers who are already users of monitoring information see the greatest value in the information [40], in part because those not currently using the information may be "unconsciously incompetent" with regard to the potential use of the information [41].

\section{Conclusion}

This study informs the literature on proactive drought response and the current and potential role of drought early warning in supporting it. Smit and Skinner [16] classify adaptation in terms of intent, purposefulness, timing, duration, scale, responsibility, and form. The intent of decisions can be considered in light of the managers' goals and the particular impacts that managers hope to avoid or minimize [15]. And, the proactive versus reactive nature of decisions may depend upon the ultimate intent of the decisions. Thus, it is important to consider drought response within the context of decision-making goals and calendars in order to understand the implications for earlier versus later response, lending support to the need for better understanding and documentation of crop-specific decision calendars (e.g., $[9,17])$.

Findings provide support for encouraging Great Plains range-based livestock producers to make stocking decisions based on spring drought conditions, regardless of later 
TABLE 4: Factors affecting drought impacts.

\begin{tabular}{|c|c|c|c|c|c|c|}
\hline & $\begin{array}{c}\text { Loss of pasture } \\
\text { hay yield }\end{array}$ & $\begin{array}{l}\text { Loss of range } \\
\text { productivity }\end{array}$ & $\begin{array}{c}\text { Loss of range } \\
\text { health or diversity }\end{array}$ & $\begin{array}{l}\text { Loss of livestock gain } \\
\text { or productivity }\end{array}$ & $\begin{array}{l}\text { Loss of net } \\
\text { income }\end{array}$ & $\begin{array}{c}\text { Loss of cash } \\
\text { reserves or savings }\end{array}$ \\
\hline SPEI & $-55.46^{* *}(188)$ & $-32.96^{* *}(171)$ & $-43.96^{* *}(111)$ & $-13.24^{* *}(112)$ & $-9.32(175)$ & $3.49(119)$ \\
\hline $\begin{array}{l}\text { Timing of purchasing } \\
\text { supplemental feed }\end{array}$ & $1.31(104)$ & $1.74(91)$ & $1.03(60)$ & $-2.11^{* *}(60)$ & $-0.70(87)$ & $-5.10^{* *}(59)$ \\
\hline $\begin{array}{l}\text { Timing of early grazing } \\
\text { fall/winter pastures }\end{array}$ & $3.21(103)$ & $0.87(97)$ & $1.87(63)$ & $-0.33(63)$ & $0.18(91)$ & $-2.80(58)$ \\
\hline Timing of destocking & $1.56(88)$ & $3.49^{* *}(85)$ & $4.78^{* *}(60)$ & $-0.78(58)$ & $-0.03(77)$ & $-0.49(51)$ \\
\hline $\begin{array}{l}\text { Timing of culling } \\
\text { breeding herd }\end{array}$ & $0.26(71)$ & $0.98(60)$ & $-0.58(44)$ & $-2.22(45)$ & $-1.28(59)$ & $0.73(43)$ \\
\hline
\end{tabular}

Reporting coefficients, significance of test that coefficient is different from 0 , and $(n)$. For SPEI, the coefficient is determined without other covariates. For other predictors, coefficients are determined when controlling for SPEI. Data sources: 2016 survey, SPEI (droughtatlas.unl.edu). ${ }^{*} p<0.10 ;{ }^{* *} p<0.05$.

TABLE 5: Factors affecting perceived capacity to improve drought response.

\begin{tabular}{lcc}
\hline & Would have acted differently with information & $\begin{array}{c}\text { Would have seen less impact if acted } \\
\text { differently }\end{array}$ \\
\hline SPEI & $0.14(241)$ & $0.29(239)$ \\
Timing of purchasing supplemental feed & $-0.05(109)$ & $0.08(109)$ \\
Timing of early grazing fall/winter pastures & $-0.04(109)$ & $0.35^{*}(108)$ \\
Timing of destocking & $0.11(92)$ & $0.32^{* *}(93)$ \\
Timing of culling breeding herd & $0.03(68)$ & $0.10(68)$ \\
Use/influence on-farm monitoring & $0.41^{* *}(236)$ & $0.21(235)$ \\
Use/influence own assessment of conditions & $0.23^{*}(235)$ & $0.12(235)$ \\
Use/influence local extension & $0.23(236)$ & $0.05(235)$ \\
Use/influence NWS & $0.43^{* *}(237)$ & $0.17(236)$ \\
Use/influence U.S. Drought monitor & $0.20(235)$ & $0.12(234)$ \\
Use/influence USDA resources & $0.04(236)$ & $-0.05(235)$ \\
Use/influence TV/radio & $0.04(234)$ & $0.10(233)$ \\
\hline
\end{tabular}

Reporting coefficients listed in log-odds units, significance of test that coefficient is different from 0 , and $(n)$. For SPEI, the coefficient is determined without other covariates. For other predictors, coefficients are determined when controlling for SPEI. Data sources: 2016 survey, SPEI (droughtatlas.unl.edu). ${ }^{*} p<0.10 ;{ }^{* *} p<0.05 . n$ varies, dependent upon variable $n$ (listed in Table 1 ).

season precipitation [33]. This study shows that actions taken with the intent of avoiding rangeland harm only do so when taken proactively and as soon as it can be determined that drought is likely to reduce forage growth. The same actions, taken reactively after damages have already occurred, have the effect of coping with damages instead of lessening them. Though this study focused only on a one-year flash drought, waiting to destock pastures was associated with greater losses to range productivity, health, and diversity. And, respondents who waited to destock saw the potential for less harm to their operations had they acted differently or sooner. These findings are important because, while range and pastures may be likely to recover after a one-year drought [42], degraded range health increases the vulnerability of the operation to harm from future multi-year droughts and recurring drought events. Future research should examine the connections between drought, management, and impacts to provide additional analysis of feedback relationships such as these that are difficult to quantify.

A key finding of this study is that the timing of drought response actions did not align with the timing of drought development. Spring drought conditions did not, for most respondents, lead them to begin taking drought response action in the spring or summer months. More research is needed to investigate other factors influencing the timing of these decisions. Respondents' use of drought early warning information did not influence the timing of their actions, though federal disaster assistance did. Respondents' efforts to monitor and pay attention to environmental cues, through on-farm moisture monitoring and/or other means of assessing conditions, may have led them to strategically alter their timing of response. This supports efforts to increase on-farm monitoring as a strategy for increasing proactive drought response in the future.

This study suggests opportunities for improved management, given the development of improved drought early warning information that clearly links emerging drought conditions with expected impacts and actions that can be taken to minimize those impacts. New decision support tools, such as the USDA GrassCast Tool, should be explored and developed further as strategies to provide more management-specific early warning of drought to rangeland managers (http://grasscast.agsci.colostate.edu/). This study provides evidence of opportunities to use such tools in concert with drought early warning information to improve the timing of rangeland managers' drought responses and the outcomes of drought management.

\section{Data Availability}

The drought monitoring datasets used to support the findings of this study are available from the corresponding 
author upon request. Station-based datasets for the SPI and SPEI can be accessed at https://droughtindex.unl.edu. Survey descriptive statistics are available from the corresponding author upon request.

\section{Conflicts of Interest}

The authors declare that there are no conflicts of interest regarding the publication of this paper.

\section{Acknowledgments}

The authors are grateful to the agricultural producers and advisors who pretested the survey and to the producers who participated in the survey. The authors are also grateful to Yared Ashenafi Bayissa for calculating countylevel SPEI values and to Deborah Wood for proofreading. Errors remain the authors' own. This work was supported by the National Oceanic and Atmospheric Administration (NOAA) Sectoral Application Research Program (SARP) via grants NA160AR4310131 and NA16OAR4310130 and by the National Integrated Drought Information System.

\section{Supplementary Materials}

Appendix A provides the full wording and formatting of questionnaire-based measured used in this analysis. (Supplementary Materials)

\section{References}

[1] International Strategy for Disaster Reduction UNISDR, Terminology on Disaster Risk Reduction, UNISDR, Geneva Switzerland, 2009.

[2] C. Knutson and T. Haigh, "A drought-planning methodology for ranchers in the Great Plains," Rangelands, vol. 35, no. 1, pp. 25-33, 2013.

[3] J. D. Derner and D. J. Augustine, “Adaptive management for drought on rangelands," Rangelands, vol. 38, no. 4, pp. 211-215, 2016.

[4] M. Svoboda, D. LeComte, M. Hayes et al., "The drought monitor," Bulletin of the American Meteorological Society, vol. 83, no. 8, pp. 1181-1190, 2002.

[5] M. C. Lemos, C. J. Kirchhoff, and V. Ramprasad, "Narrowing the climate information usability gap," Nature Climate Change, vol. 2, no. 11, pp. 789-794, 2012.

[6] C. J. Kirchhoff, M. Carmen Lemos, and S. Dessai, "Actionable knowledge for environmental decision making: broadening the usability of climate science," Annual Review of Environment and Resources, vol. 38, no. 1, pp. 393-414, 2013.

[7] M. Buchanan-Smith, "Role of early warning systems in decision making processes," in Early Warning Systems for Drought Preparedness and Drought Management, World Meteorological Organization, Geneva, Switzerland, 2000.

[8] R. S. Pulwarty and M. V. K. Sivakumar, "Information systems in a changing climate: early warnings and drought risk management," Weather and Climate Extremes, vol. 3, pp. 14-21, 2014.

[9] T. Haigh, E. Takle, J. Andresen, M. Widhalm, J. S. Carlton, and J. Angel, "Mapping the decision points and climate information use of agricultural producers across the U.S. Corn Belt," Climate Risk Management, vol. 7, pp. 20-30, 2015.
[10] B. Walker, S. R. Carpenter, J. M. Anderies et al., "Resilience management in social-ecological systems: a working hypothesis for a participatory approach," Conservation Ecology, vol. 6 , no. 1, p. 14, 2002.

[11] S. E. Hollinger, "Meteorological forecasting for agricultural production," in Systems Analysis and Modeling in Food and Agriculture, K. C. King, D. H. Fleisher, and L. F. Rodriguiz, Eds., p. 488, EOLSS Publications, Oxford, UK, 2009.

[12] C. T. Bastian, C. Ponnamaneni, P. Mooney et al., "Range livestock strategies given extended drought and different price cycles," ASFMRA, pp. 153-163, 2009.

[13] D. L. Coppock, "Ranching and multiyear droughts in Utah: production impacts, risk perceptions, and changes in preparedness," Rangeland Ecology \& Management, vol. 64, no. 6, pp. 607-618, 2011.

[14] E. Kachergis, J. D. Derner, B. B. Cutts et al., "Increasing flexibility in rangeland management during drought," Ecosphere, vol. 5, no. 6, pp. 1-14, 2014.

[15] T. R. Haigh, W. Schacht, C. L. Knutson et al., "Socioecological determinants of drought impacts and coping strategies for ranching operations in the Great Plains," Rangeland Ecology \& Management, vol. 72, no. 3, pp. 561-571, 2019.

[16] B. Smit and M. W. Skinner, "Adaptation options in agriculture to climate change: a typology," Mitigation and Adaptation Strategies for Global Change, vol. 7, no. 1, pp. 85-114, 2002.

[17] E. S. Takle, C. J. Anderson, J. Andresen et al., "Climate forecasts for corn producer decision making," Earth Interactions, vol. 18, no. 5, pp. 1-8, 2014.

[18] D. Hillier and B. Dempsey, A Dangerous Delay, Oxfam Intenational, Nairobi, Kenya, 2012.

[19] S. Davies, "Are coping strategies a cop out?," IDS Bulletin, vol. 24, no. 4, pp. 60-72, 1993.

[20] H. Wilmer, E. York, W. K. Kelley, and M. W. Brunson, ““In every rancher's mind": effects of drought on ranch planning and practice," Rangelands, vol. 38, no. 4, pp. 216-221, 2016.

[21] T. R. Shrum, W. R. Travis, T. M. Williams, and E. Lih, "Managing climate risks on the ranch with limited drought information," Climate Risk Management, vol. 20, pp. 11-26, 2018.

[22] M. K. Lindell and R. W. Perry, "The protective action decision model: theoretical modifications and additional evidence," Risk Analysis, vol. 32, no. 4, pp. 616-632, 2012.

[23] E. Kuligowski, "Predicting human behavior during fires," Fire Technology, vol. 49, no. 1, pp. 101-120, 2013.

[24] S. P. Church, T. Haigh, M. Widhalm et al., "Agricultural trade publications and the 2012 Midwestern U.S. drought: a missed opportunity for climate risk communication," Climate Risk Management, vol. 15, pp. 45-60, 2017.

[25] T. Terpstra and M. K. Lindell, "Citizens' perceptions of flood hazard adjustments: an application of the protective action decision," Environment and Behavior, vol. 45, no. 8, pp. 993-1018, 2013.

[26] M. K. Lindell and D. J. Whitney, "Correlates of household seismic hazard adjustment adoption," Risk Analysis, vol. 20, no. 1, pp. 13-26, 2000.

[27] D. A. Wilhite, "Drought as a natural hazard," in Drought: A Global Assessment, D. A. Wilhite, Ed., vol. 1, pp. 3-18, Routledge, Abingdon, UK, 2000.

[28] D. Cash, W. Clark, F. Alcock, N. Eckley, and J. Jäger, Salience, Credibility, Legitimacy and Boundaries: Linking Research Assessment and Decision Making RWP02-046, Harvard University, John F. Kennedy School of Government, Cambridge, MA, USA, 2002. 
[29] J. Otkin, T. Haigh, A. Mucia, M. C. Anderson, and C. Hain, "Comparison of agricultural stakeholder survey results and drought monitoring datasets during the 2016 U.S. Northern Plains flash drought," Weather, Climate, and Society, vol. 10, no. 8, pp. 867-883, 2018.

[30] USDA National Agricultural Statistics Service, Agricultural Prices, USDA National Agricultural Statistics Service, Washington, DC, USA, 2017.

[31] NCEI, Drought-Annual 2016 State of the Climate, National Centers for Environmental Information (NCEI), Asheville, NC, USA, 2019, https://www.ncdc.noaa.gov/sotc/drought/ 201613.

[32] D. A. Dillman, "The design and administration of mail surveys," Annual Review of Sociology, vol. 17, no. 1, pp. 225-249, 1991.

[33] A. J. Smart, B. H. Dunn, P. S. Johnson, L. Xu, and R. N. Gates, "Using weather data to explain herbage yield on three great plains plant communities," Rangeland Ecology \& Management, vol. 60, no. 2, pp. 146-153, 2007.

[34] Y. Xia, J. Sheffield, M. B. Ek et al., "Evaluation of multi-model simulated soil moisture in NLDAS-2," Journal of Hydrology, vol. 512, pp. 107-125, 2014.

[35] M. C. Anderson, J. M. Norman, J. R. Mecikalski, J. A. Otkin, and W. P. Kustas, "A climatological study of evapotranspiration and moisture stress across the continental United States based on thermal remote sensing: 1. Model formulation," Journal of Geophysical Research: Atmospheres, vol. 112, no. 10, 2007.

[36] D. W. Hosmer, S. Lemeshow, and R. X. Sturdivant, Applied Logistic Regression, Wiley, vol. 23, no. 1, Hoboken, NJ, USA, 1994.

[37] StataCorp LP, Stata Statistical Software: Release 12, StataCorp LP, College Station, TX, USA, 2011.

[38] A. J. K. Smart, J. D. Harmoney, M. B. Scasta et al., "Forum: critical decision dates for drought management in central and norther Great Plains rangelands," Rangeland Ecology and Management, vol. 72, 2019.

[39] B. Dunn, A. Smart, and R. Gates, "Barriers to successful drought management: why do some ranchers fail to take action?," Rangelands, vol. 27, no. 2, pp. 13-16, 2005.

[40] J. R. Ziolkowska and J. Zubillaga, "Importance of weather monitoring for agricultural decision-making - an exploratory behavioral study for Oklahoma Mesonet," Journal of the Science of Food and Agriculture, vol. 98, no. 13, pp. 4945-4954, 2018.

[41] L. Turner, L. Irvine, and S. Kilpatrick, "Incorporating data into grazing management decisions: supporting farmer learning," Animal Production Science, 2019.

[42] R. K. Heitschmidt, K. D. Klement, and M. R. Haferkamp, "Interactive effects of drought and grazing on northern great plains rangelands," Rangeland Ecology \& Management, vol. 58, no. 1, pp. 11-19, 2005. 



The Scientific

\section{World Journal}
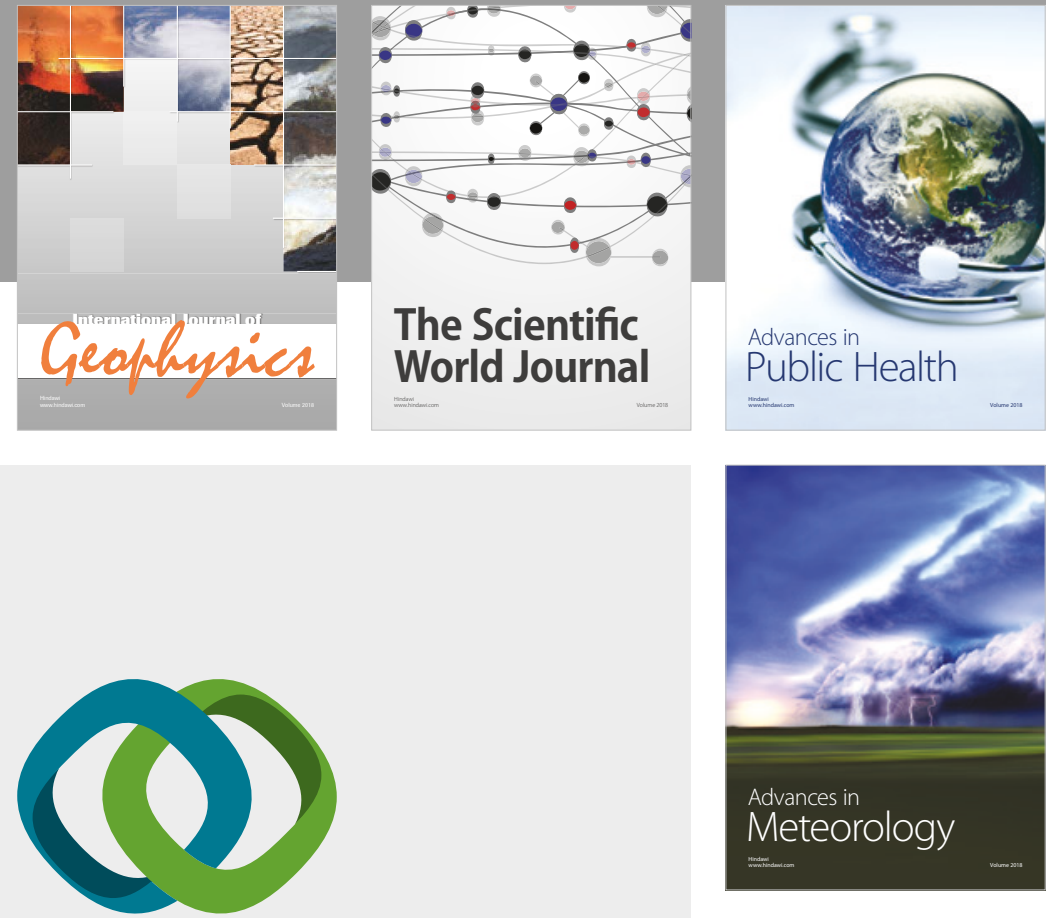

Advan

Public Health

\section{Hindawi}

Submit your manuscripts at

www.hindawi.com
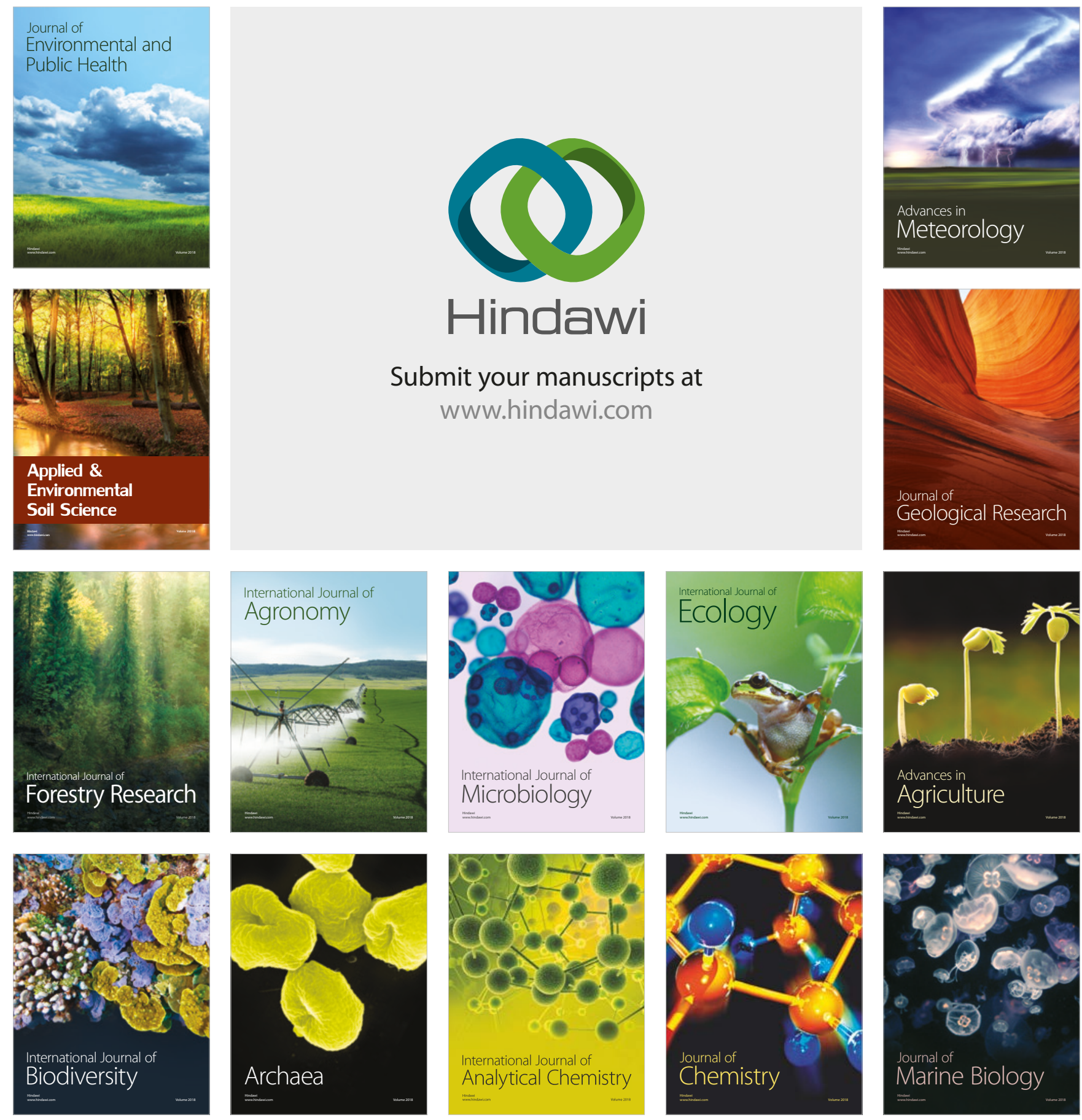